УДК 622.276

СОПРОВОЖДЕНИЕ БУРЕНИЯ ГОРИЗОНТАЛЬНЫХ СКВАЖИН

НА ВОСТОЧНО-МЕССОЯХСКОМ МЕСТОРОЖДЕНИИ

В УСЛОВИЯХ ВЫСОКОЙ ЛАТЕРАЛЬНОЙ

НЕОДНОРОДНОСТИ ПЛАСТА ПК

\author{
И. В. Коваленко ${ }^{1}$, С. К. Сохошко ${ }^{2}$, Д. И. Тенгелиди ${ }^{1}$, И. М. Ниткалиев ${ }^{1}$ \\ ${ }^{1}$ ООО «Газпромнефть - НТЦ», г. Тюмень, Россия \\ ${ }^{2}$ Тюменский индустриальный университет, г. Тюмень, Россия
}

Аннотация. В работе описаны роль учета латеральной неоднородности континентальных отложений, актуализация стратегии бурения и прогнозирование элементов залегания пласта. Цель работы заключается в описании подходов для подбора наиболее оптимального расположения скважины при планировании бурения, с учетом постоянно пополняемой и обновляемой геологической информации о пласте.

Ключевые слова: континентальный генезис отложений; неднородность; стратегия бурения

\title{
DRILLING STRATEGY OF HORIZONTAL WELLS \\ AT THE VOSTOCHNO-MESSOYAKHSKOYE OIL FIELD \\ IN CONDITIONS OF HIGH LATERAL HETEROGENEITY OF THE PK 1-3 $_{3}$ FORMATION
}

\author{
I. V. Kovalenko ${ }^{1}$, S. K. Sokhoshko ${ }^{2}$, D. I. Tengilidii ${ }^{1}$, I. M. Nitkaliev ${ }^{1}$ \\ ${ }^{1}$ LLC «Gazpromneft - NTC», Tyumen, Russia \\ ${ }^{2}$ Industrial University of Tyumen, Tyumen, Russia
}

\begin{abstract}
The article describes the role of the account the lateral heterogeneity of the continental sediments, updating of drilling strategy, and prediction of the occurrence of the formation. Our aim is to describe approaches for the selection of the most optimal arrangement of wells in drilling strategy, taking into account the constantly updated geological information about the formation.
\end{abstract}

Key words: continental genesis of sediments; heterogeneity; drilling strategy

Введение

На текущий момент пласт ПК 1 -3 Восточно-Мессояхского месторождения находится на этапе полномасштабного эксплуатационного бурения. Трудности разработки таких отложений описаны во многих источниках, и существует множество статей, освещающих данную проблематику [1-3]. В таких отложениях одним из обязательных условий стратегии бурения становится планирование пилотного ствола, способствующего изучению геологического разреза и дальнейшей успешной проводки горизонтальных стволов. Однако геология данных отложений не позволяет с достаточной степенью уверенности сказать, какое количество данных скважин пилотов будет достаточным. Пример латеральной и вертикальной неод- 
нородности Восточно-Мессояхского месторождения показан на рисунке 1. На расстоянии 400 м между скважинами наблюдается резкое изменение не только качества коллекторов, но и характера их насыщения.

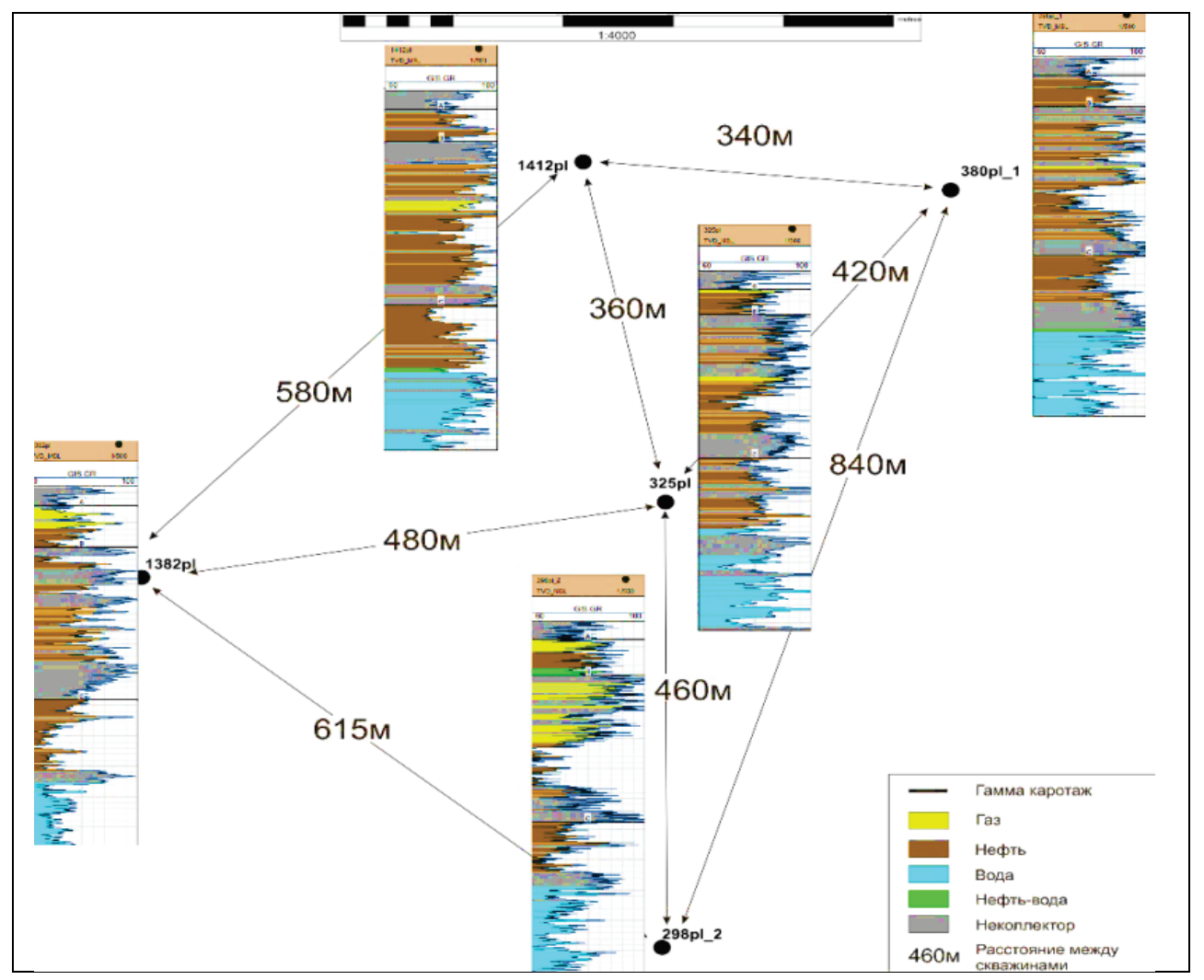

Рис. 1. Обзорная схема расположения пилотов и неоднородность разреза по вертикали

В связи с этим стратегия бурения горизонтальных скважин не должна являться статичной, а должна постоянно адаптироваться под новую получаемую геологическую информацию, в том числе и в режиме реального времени. Таким образом, геонавигация при сопровождении бурения является неотъемлемой частью такой стратегии.

На рисунке 2 схематично изображены эволюция стратегии бурения пласта

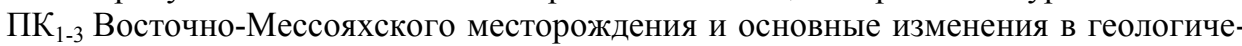
ской концепции отложений.
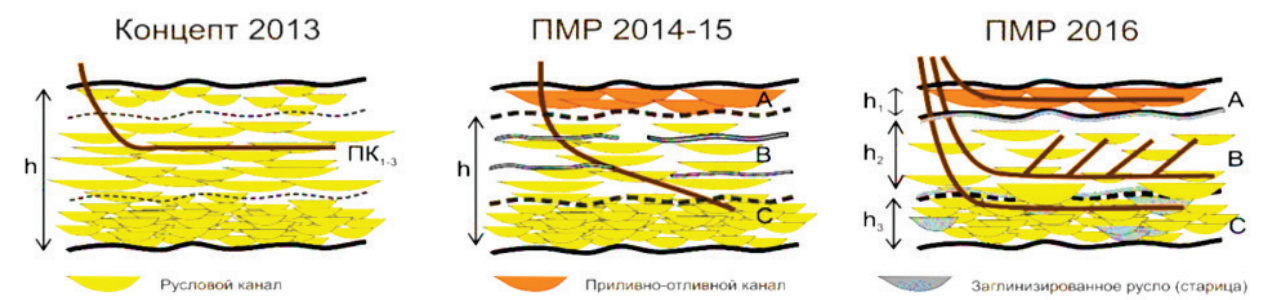

Рис. 2. Изменение геологической концепции и стратегии бурения с годами 
Полномасштабная разработка 2014-2015 гг.

В процессе эксплуатационного бурения подтвердилась высокая неднородность распределения песчаника и коллекторских свойств как по разрезу, так и по латерали. В результате выполненных исследовательских работ на сегодня сформировано следующее представление о геологическом строении продуктивного интервала: разрез состоит из трех интервалов (циклитов $A, B, C$ ), разделенных первоначально поверхностями затопления. Условия формирования отложений каждого циклита установлены по результатам седиментологического анализа данных керна и материалам региональной геологии: отмечается переход от континентальных отложений (система меандрирующих русел) в нижней части (циклит $C$ ), до мелководноморских отложений (фронт дельты) в кровельной части (циклит $A$ ).

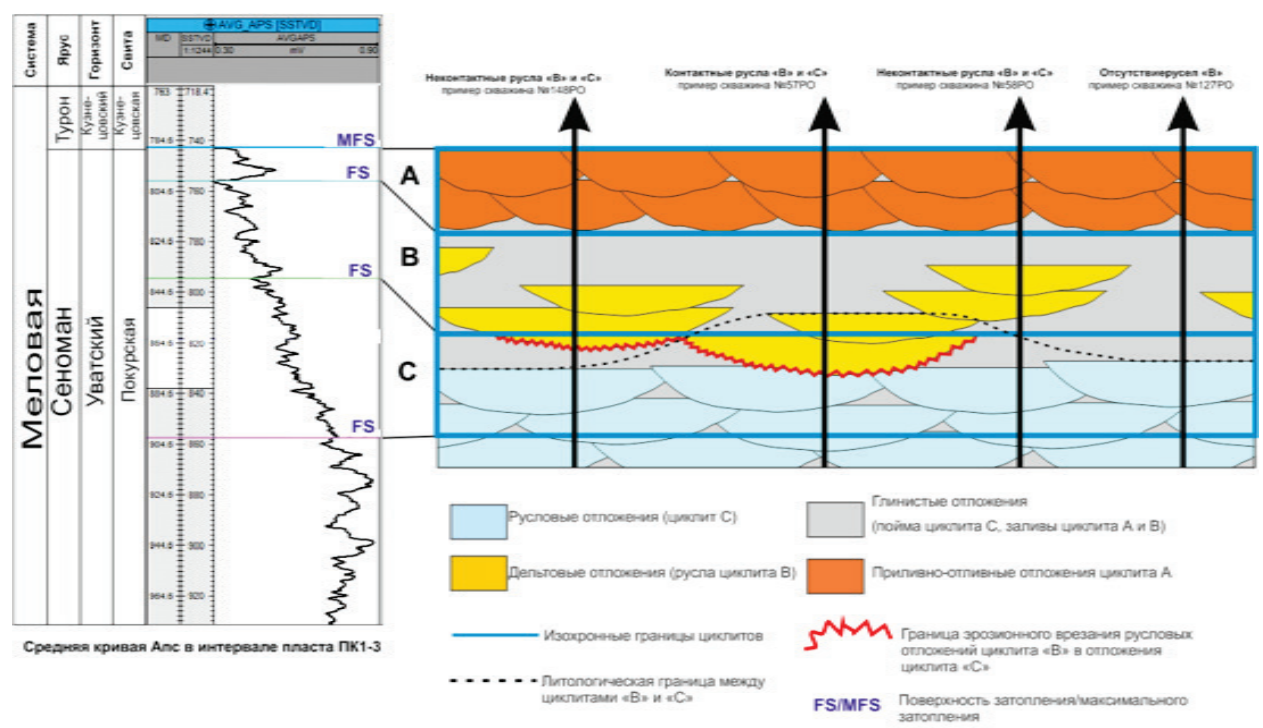

Рис. 3. Принципиальная схема строения продуктивного разреза

На рисунке 3 приведена принципиальная схема строения продуктивного разреза. Анализируя кривые геофизических исследований, можно достаточно уверенно идентифицировать границу между циклами $A$ и $B$. Однако при корреляции границы между интервалами $B$ и $C$ возникают трудности, и в первую очередь в местах предполагаемых эрозионных врезов каналов циклита $B$. В этой связи для определения изначального положения циклитов реализован способ создания средней кривой $\alpha_{\text {пс }}$, описанный в работе [4]. На ее основе установлено первоначальное (стратиграфическое) положение границ циклитов, которое затем скорректировано для границы между циклитами $B$ и $C$ : граница проведена по кровле выдержанных коллекторов, приуроченных к русловым отложениям континентальной равнины (коллектора характеризуются большой мощностью и выдержанностью по разрезу, в большинстве случаев отсутствием мощных глинистых пропластков). Такое разделение разреза пласта ПК 1-3 позволяет разделить разрез по контрасту фильтрационно-емкостных свойств (ФЕС). Благодаря выполненной типизации разрезов скважин с привлечением данных сейсморазведочных исследований удалось закартировать области развития преимущественно русловых отложений, обладающих улучшенными ФЕС.

Помимо установленных закономерностей распределения отложений по площади и разрезу, уточнена методика расчета проницаемости коллекторов, переоценка которой стала одной из ключевых проблем полномасштабной разра- 
ботки (ПМР) 2014-2015 гг. Выполненный объем керновых исследований в совокупности с имеющимися методами ГИС позволяет количественно оценить долю глинистой составляющей порового пространства, которая оказывает прямое влияние на проницаемость.

На рисунке 4 приведены кросс-плоты зависимостей проницаемости от открытой пористости (а) и от эффективной пористости (б), учитывающей долю глинистой составляющей. Как видно из примера, во втором случае разброс фактических значений проницаемости от рассчитанных намного ниже, чем в первом.
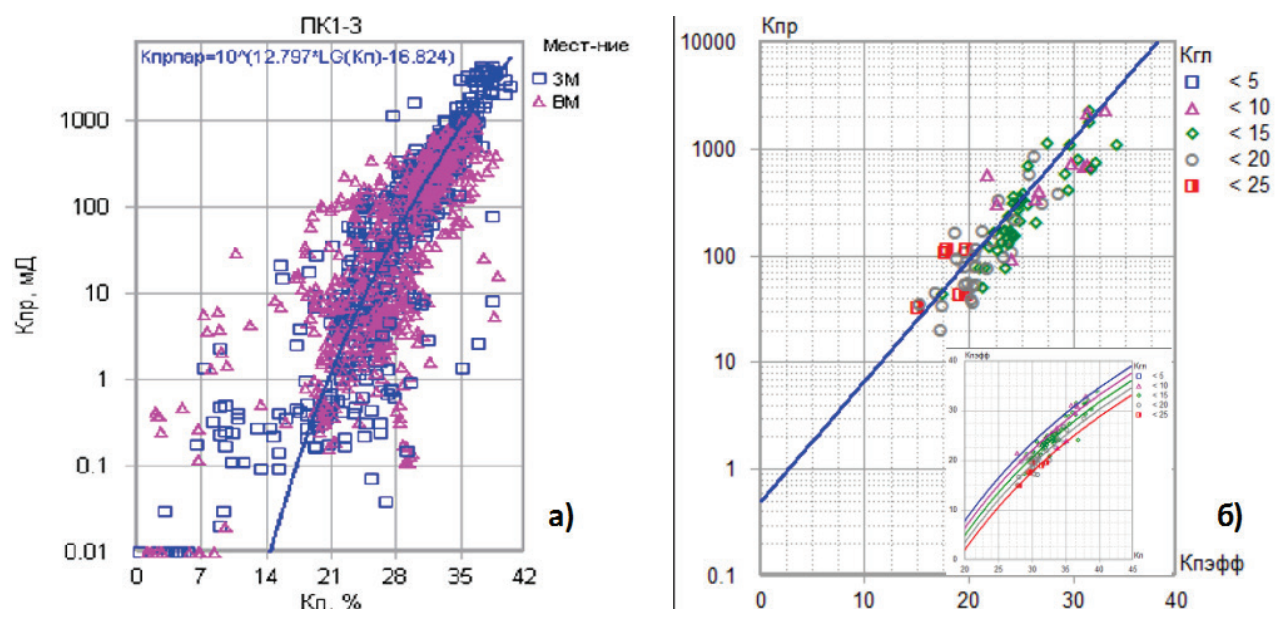

Рис. 4. Зависимость проницаемости от открытой пористости (a) и от эффективной пористости (б)

Новая стратегия бурения (полномасштабная разработка 2016 г.)

Обновление концептуальных представлений на основе новых скважинных данных фонда ПМР (18 горизонтальных и 9 пилотных стволов) выявило необходимость пересмотра стратегии бурения с целью оптимизации профиля добычи, что главным образом связано со следующими причинами:

- значительное недостижение проектных дебитов скважин ПМР, пробуренных в циклит $B$;

- $\quad$ наличие зон гидродинамической разобщенности циклита $A$ и циклитов $B+C$;

- недоизученность потенциала циклита $A$;

- наличие локальных газонасыщенных и водонасыщенных пропластков;

- существенные различия эффективности проводки скважин в зависимости от принадлежности к циклиту;

- неподтверждение прогнозных параметров на удалении уже первых сотен метров от опорного пилотного ствола в циклите $B$.

Комплекс сформированных мероприятий доизучения залежи, направленный на снятие и снижение вышеописанных неопределенностей, включает в себя следующие ключевые решения:

- ориентация зон первоочередного бурения на наиболее уверенные, выдержанные отложения циклита $C$ в районы с нефтенасыщенными толщинами (более $12-15$ м), рентабельными для разработки;

- запись гамма-гамма плотностного (ГГК-П) и нейтрон-нейтронного каротажей (ННК) в транспортной секции ствола для оценки характера насыщения циклитов $A$ и $B$, а также изучения их ФЕС при бурении скважин на циклит $C$; 
- опытно-промышленные работы (ОПР) в безгазовый циклит $A$ для оценки продуктивности скважин, планируемых в краевые зоны залежи;

- ОПР по бурению горизонтальных стволов с многозабойным заканчиванием и бурению скважин по технологии Fishbone.

В рамках ОПР куста № 38 были пробурены 3 скважины с разным количеством отростков Fishbone, основные горизонтальные стволы при этом имеют как ниспадающие, так и восходящие профили с успешными срезками отростков Fishbone (рис. 5). Наличие мощного руслового канала позволило провести горизонтальный ствол скв. 182 преимущественно по коллектору с высокими ФЕС на абсолютную отметку 797 м, при этом вовлекая в разработку отделенные расчлененными отложениями коллектора на абсолютную отметку 777-780 м. Скважина $248+4 \mathrm{FB}$ была пробурена в разрезе пойменных отложений, что позволит оценить эффект применения технологии Fishbone в разных геологических условиях.
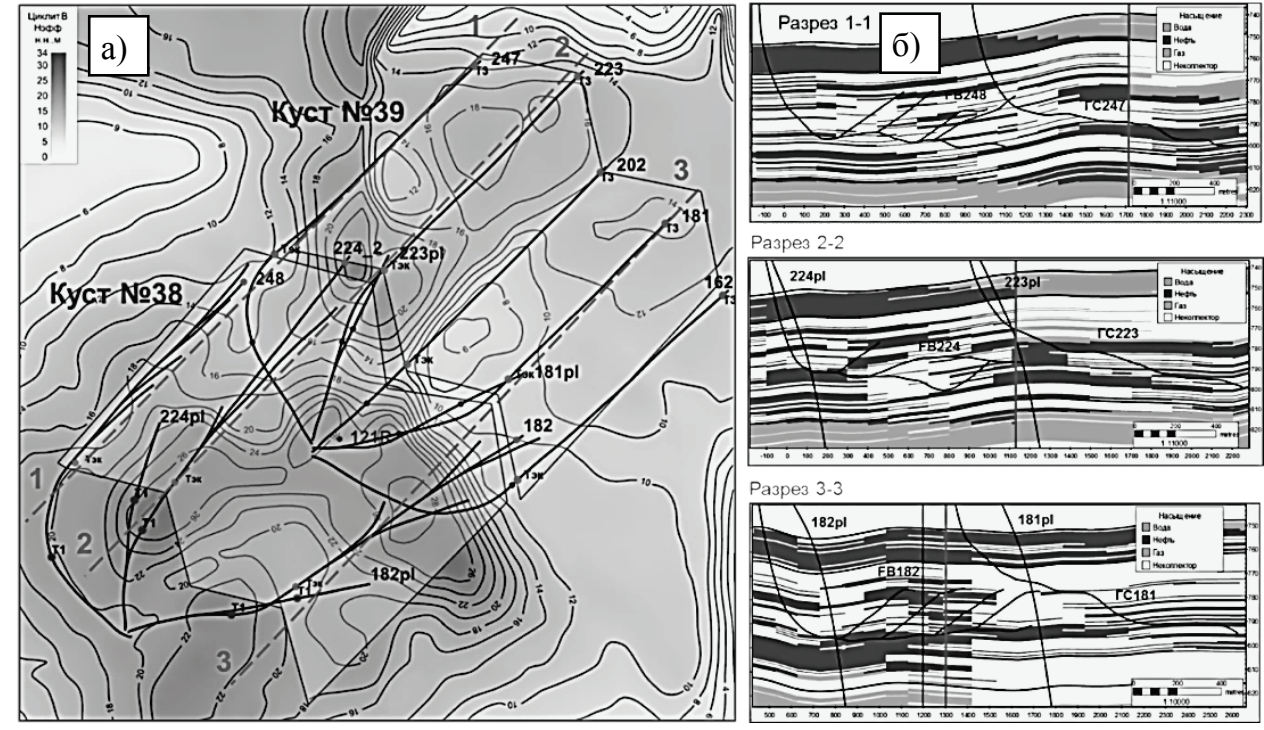

Рис. 5. Схема расположсния скважин на карте эффективных нефтенасыщенных толщцин циклита В (а) и разрезы вдоль горизонтальных скважин (б)

Анализ стартовых показателей работы скважин на 15-е сутки показал эффективность использования данной технологии как в сильно расчлененных коллектоpax с низкими ФЕС, так и при наличии высокопроницаемых каналов в разрезе, прирост продуктивности оценивается на уровне $55 \%$.

Анализ результатов геонавигации и факта работы скважин пробуренного фонда свидетельствует о том, что наиболее эффективным способом проводки траектории является стратиграфическое бурение, когда профиль скважины параллельно повторяет изменения структуры, а в случае потери коллектора проводка осуществляется в зоне статистически наиболее вероятного вскрытия русловых отложений с большим шансом вскрытия коллекторов с высокими ФЕС.

Геонавигация горизонтальных стволов скважин в континентальных отложениях - весьма наукоемкий процесс, требующий наличия обширного геофизического комплекса исследований по причине отсутствия уверенных прослеживаемых границ-маркеров для привязки синтетических каротажей к опорным пилотным стволам. Кроме того, залежь пласта ПК $1-3$ Восточно-Мессояхского месторождения осложнена амплитудными и малоамплитудными разломами, которые могут стать причиной наличия резких границ «коллектор - неколлектор», фиксируемых ме- 
тодами LWD вдоль направления бурения стволов скважин. Соответственно, от результата интерпретации этой границы (связано ли это со структурными особенностями или же с изменением фациальной зоны) зависит выбор решения. С целью сужения диапазона неопределенности в компоновку LWD включены азимутальные плотностные каротажи (имиджеры), определяющие структурные и геологические особенности элементов залегания. Анализ углов падения сейсмической структурной поверхности, привязанной к фактическим отбивкам пилотных стволов, в радиусе 100 м вдоль пробуренных горизонтальных скважин, отображает отсутствие резких изменений структуры (рис. 6), в то время как имиджеры показывают гораздо более широкий диапазон изменения элементов залегания, что, вероятно, связано с размерностью исследуемого пространства, однако несоответствие фактических поверхностей и интерпретируемых свидетельствует о большем вкладе аккреционных комплексов с косослоистыми текстурами отложений циклитов $B+C$. Поэтому потеря или встреча коллектора в данных геологических обстановках в первую очередь ассоциируются с фациальными, а не структурными границами, что подтвердилось бурением последующих скважин куста.

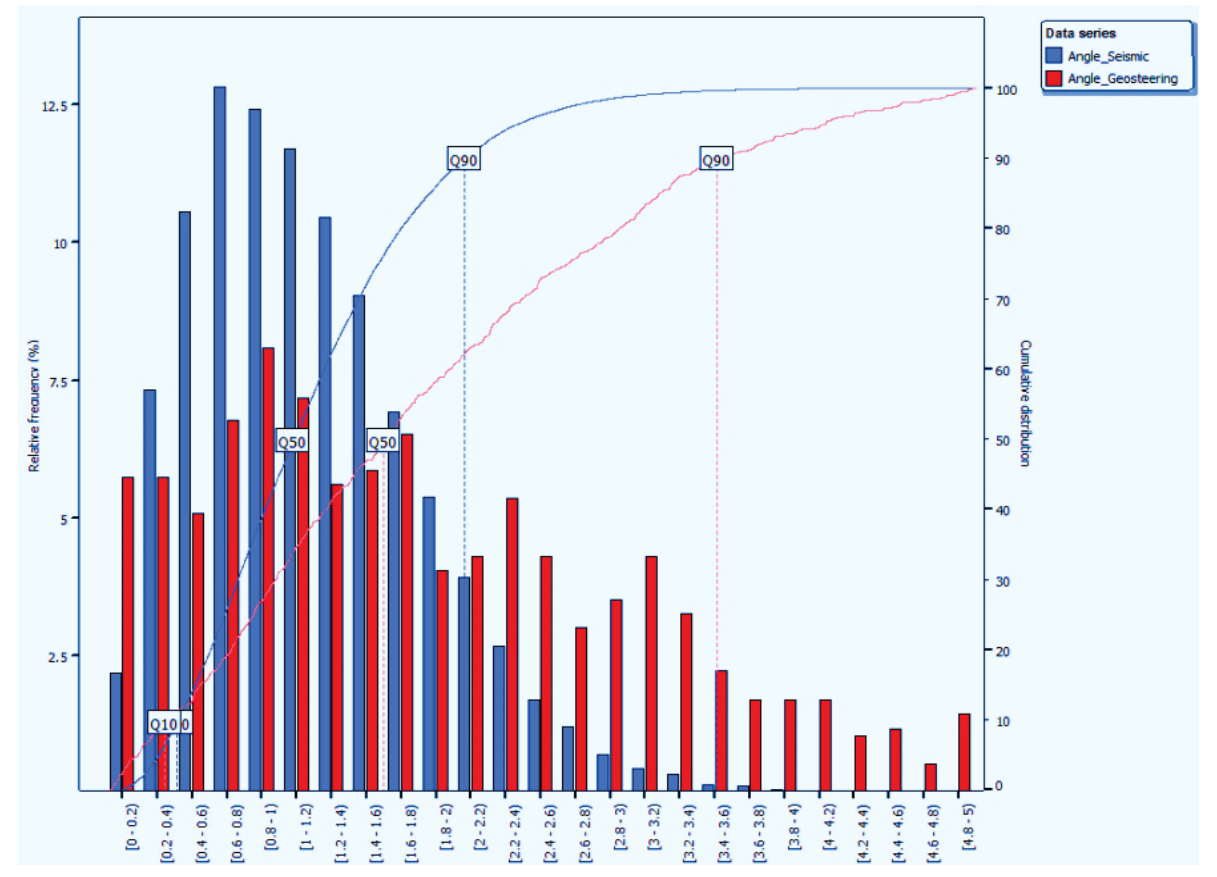

Рис. 6. Гистограммы распределения углов падения по структурной поверхности и результаты интерпретации имиджа плотности

Однако стоит отметить, что в неразбуренных зонах среднеквадратическая ошибка сейсмической поверхности достигает 10-15 м, поэтому благодаря качественной интерпретации имиджей удается формировать представление о структурах на забое горизонтальных скважин, нацеленных на циклиты $B+C$, порой не изученных бурением пилотных стволов. Вклад данного метода наблюдается при сопровождении скважин на периклинальных областях района бурения, для которых характерны градиентные зоны со значительными углами падения. Целевым объектом краевых зон является безгазовый циклит $A$, представленный мелководноморскими отложениями, в значительной степени выдержанными по площади. Примером геонавигации в такой обстановке является скв. 1163 куста № 38 (рис. 7), проведенная с эффективной длиной по коллектору $90 \%$. 


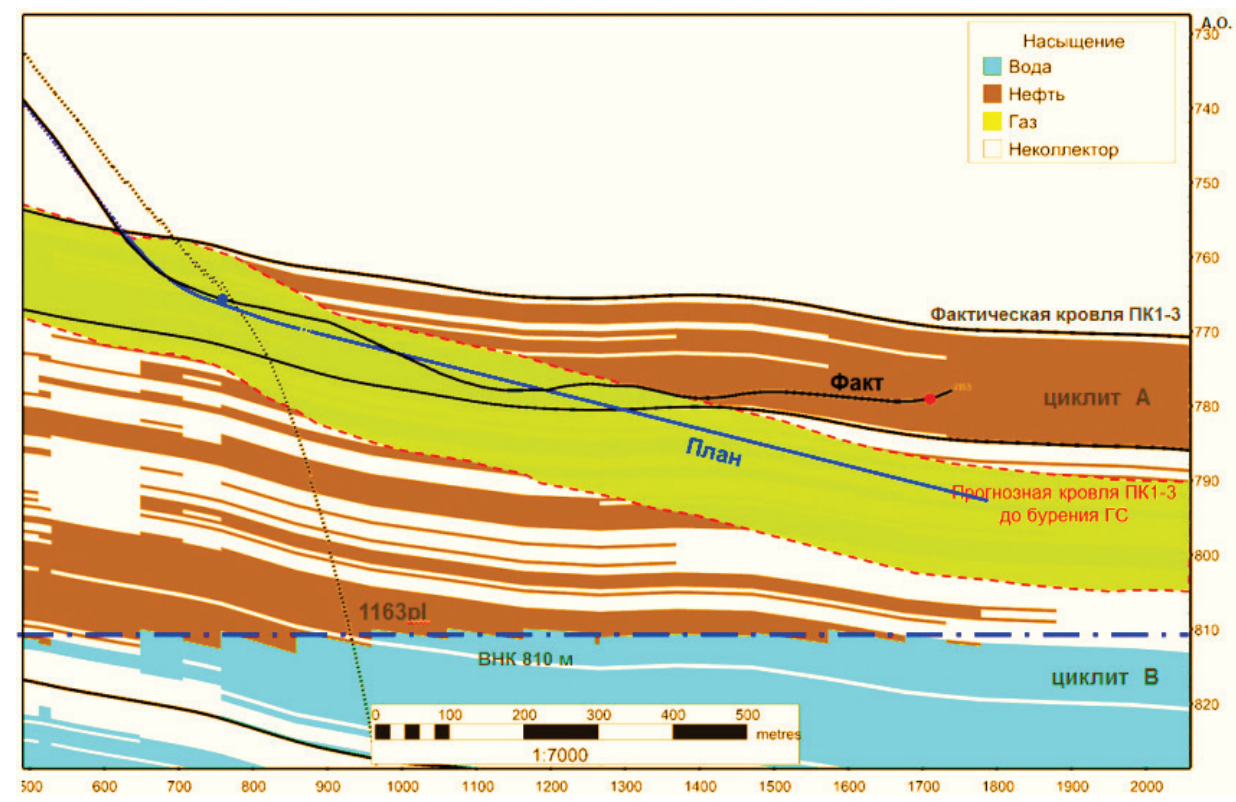

Рис. 7. Разрез по кубу насыщения вдоль горизонтальной скв. 1163

Попытка учета латеральной неоднородности на основе сейсмических данных была предпринята в районе кустов № 17-18 (рис. 8).

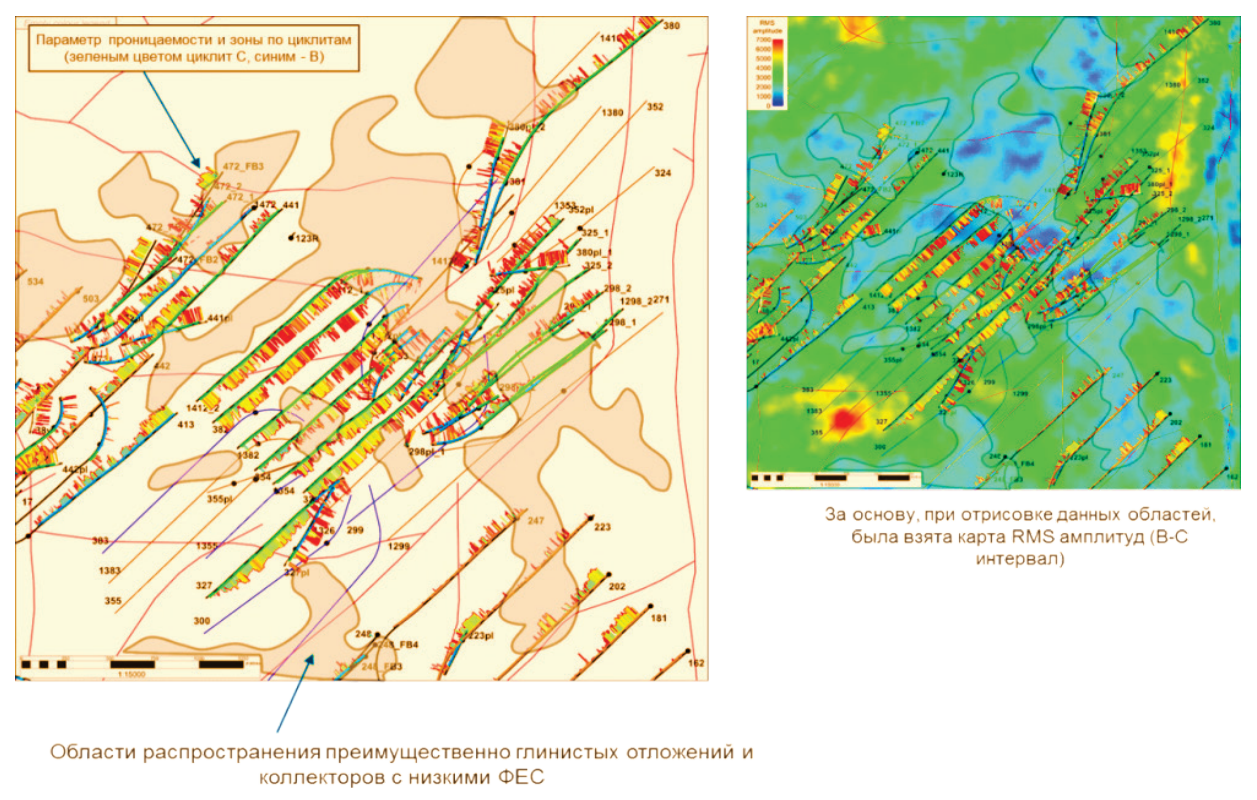

Рис. 8. Концептуальное геологическое представление района бурения кустов № 17-18

Несмотря на ориентацию скважин в циклит $C$, где эффективность проходки по статистическим данным составляет 80 \%, часть скважин попали в зону с развитием преимущественно глинистых отложений, вероятнее всего сформированных в условиях старицы или поймы. Пробурив несколько неуспешных скважин и получив качественную корреляцию с параметром RMS, было принято решение отказаться от 
бурения скважины, попавшей в зону с максимальным развитием заглинизированной области, а также увеличить количество пилотных стволов, и изменить очередность бурения на кустах.

\section{Выводы}

Резюмируя все вышесказанное, можно представить текущую стратегию бурения следующим образом:

- бурение уверенных зон циклита $C$, параллельное изучение вышележащего разреза — поиск «sweetspots» в циклите $B$, концептуальная отрисовка изменения русловых тел на основе корреляции скважинных данных;

- использование статистических данных по пробуренному фонду для оценки потенциала скважин;

- планирование профиля скважины согласно стратиграфическому залеганию пласта;

- учет интерпретации имиджей, в первую очередь в краевых зонах;

- учет несогласного характера залегания отложений на границе циклитов $B$ и $C$.

Библиографический список

1. State of Art in Prediction of Fluvial Sandbodies in Low Permeable Tyumen Formation of West Syberia / M. E. Martynov [et al.]. - SPE, 2014. - SPE 171171 RU.

2. Successful Application of Horizontal Well Completions for Development of Low Permeability Gas Reservoirs in a Complex Fluvial Deltaic Environment - A Case Study / H. A. Hazman [et al.]. - SPE, 2008. SPE 116542.

3. Reservoir Characterization and Modelling of Stacked Fluvial/Shallow Marine Reservoirs: What is Important for Fluid-Flow Performance and Effective Reservoir Prediction? / A. S. Shell [et al.]. - SPE, 2007. - SPE 110348

4. Зунде Д. А., Попов И. П. Методика построения сиквенс-стратиграфической модели покурской свиты // Нефтепромысловое дело. - 2015. - № 5. - С. 54-59.

Сведения об авторах

Коваленко Игорь Викторович, к. т.н., начальник отдела, ООО «Газпромнефть - НТЦ», 2. Tюмень, e-mail: Kovalenko.IV@gazpromneft-ntc.ru

Сохочко Сергей Константинович, д. т. н., профессор, Тюменский индустриальный университет, г. Тюмень, тел. 8(3452)283027, e-mail: sksohoshko@mail.ru

Тенгелиди Дмитрий Иванович, ведущий специиалист, ООО «Газпромнефть-НТЦ», 2. Тюмень, e-mail: Tengelidi.DI@gazpromneft-ntc.ru

Ниткалиев Ильнур Маратович, главньй специиалист, ООО «Газпромнефть - НТЦ». 2. Тюмень, e-mail: Nitkaliev.IM@gazpromneft-ntc.ru
Information about the authors

Kovalenko I. V., Candidate of Engineering, Head of the Department, LLC "Gazpromneft NTC», Tyumen, e-mail: Kovalenko.IV@gazpromneftntc.ru

Sokhoshko S. K., Doctor of Engineering, Professor Industrial University of Tyumen, phone: 8(3452)283027,e-mail: sksohoshko@mail.ru

Tengilidi D. I., Lead Specialist, LLC «Gazpromneft-NTC», Tyumen, e-mail: Tengelidi. DI@gazpromneft-ntc.ru

Nitkaliev I. M., Chief Specialist, LLC «Gazpromneft-NTC», Tyumen, e-mail: Nitkaliev.IM@gazpromneft-ntc.ru 